\section{Unusual Nosocomial Exposure to H1N1 Influenza Virus via Open-Chest Cardiac Massage}

To the Editor-During the "fall wave" of the "swine" H1N1 influenza pandemic, there was an increase in the number of cases in the New York area, compared with the initial "herald wave" after the pandemic began in the spring of 2009.' As expected, with an increase in the number of cases during the pandemic, the potential for nosocomial transmission increased. As during the herald wave of the H1N1 influenza pandemic, the greatest risk to healthcare workers (HCWs) in terms of nosocomial transmission of H1N1 influenza virus was a failure to recognize patients with potential H1N1 influenza, resulting in a delay in the institution of influenza precautions. Nosocomial transmission of $\mathrm{H} 1 \mathrm{Nl}$ influenza virus occurred during the herald wave of the pandemic and either was due to a delayed recognition of H1Nl influenza, such that patients were not placed on influenza precautions, or was due to suboptimal adherence to influenza precautions for hospitalized patients with known H1N1 influenza. ${ }^{2,3}$

We report an unusual exposure of $\mathrm{H} 1 \mathrm{~N} 1$ influenza via a patient with $\mathrm{H} 1 \mathrm{~N} 1$ influenza pneumonia who was undergoing mechanical ventilation. Before the patient died, he experienced cardiac arrest, and open-chest cardiac massage was unsuccessfully used in an attempt to restore cardiac function. During the open-chest cardiac resuscitation, there was a rupture of the lungs, and a paraendotracheal tube leak provided a potential for aerosolization or droplet transmission of the H1N1 influenza virus.

A 36-year-old man had been transferred to our hospital (Winthrop-University Hospital, Mineola, New York) from another hospital. The patient had a history of upper respiratory tract symptoms. Two days before the transfer, the patient had a sudden onset of fever (temperature, $38.9^{\circ} \mathrm{C}$ $\left.\left[102^{\circ} \mathrm{F}\right]\right)$, as well as nonproductive cough, shortness of breath, and diffuse myalgias.

At the time of admission to Winthrop-University Hospital, the patient's temperature was $40^{\circ} \mathrm{C}\left(104^{\circ} \mathrm{F}\right)$, and he was tachypneic (respiratory rate, 26 breaths/minute). His clinical condition rapidly deteriorated, resulting in respiratory failure that required intubation and mechanical ventilation. Because the patient's rapid influenza A (Quick Vue A/B; Quidel) test result was negative, he was not placed on influenza precautions. A nasopharyngeal swab specimen was obtained for reverse-transcription polymerase chain reaction (RT-PCR) for H1N1 influenza.

Although the patient had no chest pain, he underwent a right heart catheterization because of unexplained tachycar- dia. He had elevated right-side pressures, an ejection fraction of $5 \%-10 \%$, and a moderately sized pericardial effusion with cardiac tamponade. At this time, a left ventricular assist device was inserted. After the patient had died, the RT-PCR results for H1N1 influenza were reported as positive.

The patient's clinical course was complicated by multiple cardiac arrests, requiring emergent pericardiocentesis and thoracotomy for cardiac massage. Measures to resuscitate him were unsuccessful, and he died of fulminant $\mathrm{H} 1 \mathrm{~N} 1$ influenza pneumonia. The patient had not received oseltamivir prophylaxis and had not received the H1N1 influenza vaccine. HCWs who were in close contact with the patient were potentially exposed to $\mathrm{H} 1 \mathrm{~N} 1$ influenza virus.

At Winthrop-University Hospital, HCWs who engage in intubation and cough-inducing procedures use N95 respirator masks and face shields to protect against exposure to aerosols or droplets. In the case presented, aerosol or droplet exposure occurred under extraordinary circumstances (ie, lung rupture, paraendotracheal tube leaks, and open-chest cardiac massage). A total of $32 \mathrm{HCW}$ sere potentially exposed to H1N1 influenza virus. In the cardiac catheterization laboratory, $13 \mathrm{HCW}$ s were exposed. In the medical intensive care unit, $10 \mathrm{HCWs}$ were potentially exposed. Also, 9 additional HCWs were exposed in the operating room. All 32 HCWs were given oseltamivir prophylaxis. Of these 32 HCWs, 2 developed an influenza-like illness but not H1N1 influenza.

We describe an unusual potential exposure of HCWs to H1N1 influenza in the cardiac catheterization laboratory, medical intensive care unit, and operating room where we treated a patient with $\mathrm{H} 1 \mathrm{~N} 1$ influenza. Because this potential mass HCW exposure occurred on a weekend, all exposed HCWs could not immediately be contacted for oseltamivir prophylaxis. Oseltamivir prophylaxis for $\mathrm{H} 1 \mathrm{~N} 1$ influenza was given to all 32 of our potentially infected HCWs during the first 72 hours after exposure. As with other $\mathrm{HCW}$ exposures to H1N1 influenza virus, the large number of HCWs exposed necessitated a time-consuming, extensive contact investigation by the Infection Control and Employee Health Service. Most fatal cases of H1N1 influenza pneumonia in young/ healthy hosts are sue to severe hypoxemia and not bacterial pneumonia ${ }^{4,5}$ This case is noteworthy, because the HCWs' exposures occurred under extraordinary circumstances (ie, in the context of lung rupture, paraendotracheal tube leak, and open-chest cardiac massage). During HiN1 influenza pandemics, if critically ill patients present with an influenza-like illness, influenza precautions (contact or droplet) should be instituted immediately, regardless of the results of rapid influenza diagnostic tests. ${ }^{1,2}$

Burke A. Cunha, MD; Uzma Syed, DO; Valsamma Thekkel, RN, MSN, CIC; Marlene Davis, PA-C 
From the Infectious Disease Division, Infection Control Section, and the Employee Health Service, Winthrop-University Hospital, Mineola, and State University of New York School of Medicine, Stony Brook, New York (all authors).

Address reprint requests to Burke A. Cunha, MD, Winthrop-University Hospital, 222 Station Plaza North, Suite 432, Mineola, NY 11501. Infect Control Hosp Epidemiol 2010; 31(7):775-776 (C) 2010 by The Society for Healthcare Epidemiology of America. All rights reserved. 0899-823X/2010/3107-0020\$15.00. DOI: 10.1086/653817

\section{R E F E R E N C ES}

1. Cunha BA, Pherez FM, Strollo S. Swine influenza (H1N1): diagnostic dilemmas early in the pandemic. Scand J Infect Dis 2009;41:900-902.

2. Cunha BA, Thekkel V, Cohan C. Swine influenzae (H1N1): contact investigation burden on infection control and employee health due to failure to institute influenza precautions on admitted patients based on negative rapid influenza A screening tests. Infect Control Hosp Epidemiol 2010;31: 102-104.

3. Cunha BA, Thekkel V, Krilov L. Nosocomial swine influenza (H1N1) pneumonia: lessons learned from an illustrative case. J Hosp Infect 2010;74: 278-281.

4. Cuhna BA. Swin influenza (H1N1) pneumonia: bacterial airway colonization common but fatalities due to bacterial pneumonia remain relatively rare. J Clin Virol 2010;47:199-200.

5. Cunha BA. Swine influenza pneumonia: clinical considerations. Infect Dis Clin North Am 2010;24:203-228.

\section{The Need for Additional Investigation of Room Decontamination Processes}

To the Editor-Given the known effectiveness of bleach in killing spores of Clostridium difficile, ${ }^{1}$ as well as the finding by Barbut et $\mathrm{al}^{2}$ of a $3.5-\log$ reduction in viable $C$. difficile spores after 5 minutes of exposure to $0.5 \%$ sodium hypochlorite solution, it is unfortunate that Barbut and colleagues were unable to more objectively evaluate the thoroughness of environmental hygiene practice before concluding that the clinical use of a hydrogen peroxide dry-mist disinfection system is "significantly more effective than $0.5 \%$ sodium hypochlorite solution at eradicating $C$. difficile spores." (p 507) Although the authors' quick audit (not described further) of compliance with disinfection procedures in 1 of the 2 study hospitals was found to be good, they specifically note that "the quality of the disinfecting process was not controlled during the study."

We believe that Barbut and colleagues' finding of a mere $50 \%$ decrease in spore contamination in bleach-treated rooms could have been the result of an "average" level of thoroughness of cleaning in the study hospitals rather than an intrinsic inferiority of the bleach system. We based this belief on published reports demonstrating that (1) suboptimal environmental hygiene is common in hospitals, as evidenced by the finding that only $48 \%$ and $44 \%$ of high-risk surfaces in 1,605 acute care hospital patient rooms and 100 intensive care unit rooms, respectively, were cleaned as part of routine terminal room disinfection in 2 independent studies; ${ }^{3,4}$ and (2) application of a commercial cleaner disinfectant product containing 5,500 ppm sodium hypochlorite by research staff was very effective in eradicating $C$. difficile spores from commonly-touched environmental surfaces in the rooms of patients with $C$. difficile infection. ${ }^{5}$ In fact, it is notable that the average residual $C$. difficile contamination rate of $2.6 \%$ in 3 studies of hydrogen peroxide vapor (HPV) published to date is essentially identical to the $1.8 \%$ residual contamination found by Eckstein and colleagues $(P>.99)$ (Table 1). ${ }^{1,6,7}$ Indeed, the fact that the latter study documented an overall reduction rate of $97 \%$ in environmental contamination, compared with an average of $89 \%$, in the 3 studies of HPV raises the possibility that thorough environmental cleaning with a hypochlorite disinfectant may be at least as effective as HPV decontamination (Table 1).

Although innovative technologies may play a role in the environmental hygiene armamentarium, their logistical complexity as well as the equipment and personnel costs of these interventions make it imperative that independent or consortium-sponsored, objectively controlled studies be undertaken to clarify the true role of these technologies. ${ }^{8}$ Such studies would be particularly important, given the evidence that improving routine hygienic practice can significantly decrease environmental contamination of "patient zone" surfaces $^{4-10}$ and reduce the transfer of healthcare-associated pathogens to susceptible patients. ${ }^{10}$ Given the considerations above, we also believe that the conclusion by Otter et $\mathrm{al}^{8}$ that HPV technology should be considered for routine use to

TABLE 1. The Impact of Hygienic Procedures on Clostridium difficile Environmental Cultures in Contaminated Patient Rooms

\begin{tabular}{|c|c|c|c|c|c|}
\hline \multirow[b]{2}{*}{ Variable } & \multicolumn{4}{|c|}{$\begin{array}{l}\text { Study that used hydrogen peroxide } \\
\text { vapor or dry mist for decontamination }\end{array}$} & \multirow{2}{*}{$\begin{array}{c}\text { Research staff application } \\
\text { of cleaner disinfectant } \\
\text { containing bleach }{ }^{\mathrm{a}}\end{array}$} \\
\hline & Boyce et $\mathrm{al}^{6}$ & Shapey et $\mathrm{al}^{7}$ & Barbut et $\mathrm{al}^{2}$ & Total & \\
\hline Before cleaning & $11 / 43(26)$ & $48 / 203(24)$ & $34 / 180(19)$ & $93 / 409(22)$ & $30 / 54(56)$ \\
\hline After cleaning & $0 / 37(0)$ & $7 / 203(3.4)$ & $4 / 180(2.2)$ & $11 / 420(2.6)^{\mathrm{b}}$ & $1 / 54(1.8)^{\mathrm{b}}$ \\
\hline Reduction in environmental contamination, $\%$ & 100 & 86 & 88 & 89 & 97 \\
\hline
\end{tabular}

NOTE. Data are proportion (\%), unless otherwise indicated.

${ }^{a}$ Eckstein et al. ${ }^{5}$

b $P>.99$. 